\title{
Synoptic, thermodynamic and agroeconomic aspects of severe hail events in Cyprus
}

\author{
S. C. Michaelides ${ }^{1}$, K. Savvidou ${ }^{1}$, K. A. Nicolaides ${ }^{1}$, A. Orphanou ${ }^{1}$, G. Photiou ${ }^{2}$, and C. Kannaouros ${ }^{2}$ \\ ${ }^{1}$ Meteorological Service, Nicosia, Cyprus \\ ${ }^{2}$ Agricultural Insurance Organization, Nicosia Cyprus
}

Received: 3 January 2008 - Revised: 19 March 2008 - Accepted: 7 April 2008 - Published: 9 May 2008

\begin{abstract}
Hail is a hazardous weather element often accompanying a thunderstorm, as a result of either thermal instability or instability associated with baroclinic synoptic-scale systems (i.e. frontal depressions). Nevertheless, instability of any kind and thunderstorm activity does not always lead to the formation of hail of adequate size to reach the ground. The broader the knowledge concerning hail events the better the understanding of the underlying thermodynamic and dynamic mechanisms, as well as the physical processes associated with its formation.

In the present study, the severe hail events that were recorded in Cyprus during the ten-year period from 1996 until 2005 were examined, first by grouping them into two clusters, namely, the "thermal instability cluster" and the "frontal depression cluster". Subsequently, the spatial and temporal evolution of the synoptic, dynamic and thermodynamic characteristics of these hail events was studied in depth. Also, the impact of hailstorms on the local economy of the island is presented in terms of the compensations paid by the Agricultural Insurance Organization of the country.
\end{abstract}

\section{Introduction}

The area of the Mediterranean is situated in the transition zone between the subtropical highs to the south and the mid latitude lows to the north, which are responsible for the prevailing westerly air flow. In this way, the prevailing climatic characteristics and their changes are related with the medium

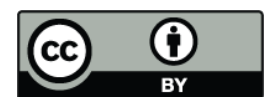

Correspondence to: S. C. Michaelides (silas@ucy.ac.cy) and upper tropospheric circulation (Reiter, 1975; Radinovic, 1987; Jacobeit, 1987).

Climatologically, the area of the Mediterranean is characterized by a long, warm and dry period (Blanchet, 1976; Maheras, 1985) lasting from 5 to 7 months (April-October) and a relatively wet and cold period, lasting for the rest of the year (September-May).

During the cold season, the area is under the influence of the southeast edge of the Siberian anticyclone, resulting in relatively high mean sea level pressure. Baroclinic depressions reach the area of Cyprus during the cold months (ElFandy, 1946; Kallos and Metaxas, 1980) mainly from the west direction (Michaelides et al., 2004; Nicolaides, 2005). Fewer depressions are reaching the area from other directions, while only isolated cases are generated or regenerated in situ (Michaelides et al., 2004; Nicolaides, 2005). These winter depressions are relatively frequent, almost one every week (Michaelides et al., 2004; Nicolaides, 2005) and have a more intense baroclinic character compared to the depressions from other Mediterranean areas (Maheras et al., 2002). Hail events are common during the cold season and the main contributor to hail events is the associated baroclinic instability.

During the hot season, the area is under the influence of the Tibetian low and baroclinic depressions are very rare. Mean sea level pressure is relatively low, with marked high temperatures mainly inland and enhanced sea breezes that penetrate several kilometers and act as the inland humid transportation mechanism. In the cases where thermal instability is increased local thunderstorms are common, generally resulting in hail events mainly inland and over the mountainous regions.

Published by Copernicus Publications on behalf of the European Geosciences Union. 
From a study of the geographical distribution of damaging hail events in Cyprus, it is evident that hail prone areas are mostly over the mountainous regions but there are also several isolated pockets over plains and coastal areas where hail occurrence appears to have some preference (see Nicolaides et al., 2008 ${ }^{1}$ ). Overall, the occurrence of hail is not a frequent one all over the island. In particular, the yearly average number of days with hail at the each of the three synoptic stations operating on the island is as follows: Paphos airport (World Meteorological Organization, WMO station no 17600) 1.3 days; Akrotiri (17 601) 2.9 days; Larnaka Airport (17 609) 2.2 days.

Knowledge of the hail size is rather circumstantial and qualitative in nature: ordinarily, hail is more often of pea-size or smaller; rarely observed hailstones are walnut-sized. Hail is more frequently observed in the afternoon hours, when the heating from below is at its maximum.

The aim of the present study is to investigate the spatial and temporal, synoptic, dynamic and thermodynamic characteristics of the severe hail events that affected the area of Cyprus during the decade from 1996 to 2005 . Such information may be considered as diagnostic; however, it can assist local weather forecasters in discriminating between baroclinic and thermal instabilities associated with hail events and their impact on local weather (Petterssen, 1956). Additionally, the economic impact of these events is presented in terms of damages produced and compensations paid by the Agricultural Insurance Organization of Cyprus (AIO).

\section{Data and methodology}

A 10 year period from 1996 to 2005 was examined in order to detect all severe hail events that were reported over the area of Cyprus. From the monthly reports issued by the Meteorological Service of Cyprus, the severe hail events that caused considerable damage either to crops or properties were identified and subsequently used in this study. These severe hail events were grouped, according to the associated prevailing synoptic situation, into two clusters, namely the "thermal instability cluster" and the "frontal depressions cluster".

In order to identify the characteristics (if any) of the clusters, several dynamic and thermodynamic parameters were examined. The dynamic parameters examined were a static stability index $(\sigma)$, the relative vorticity $(\zeta)$, the divergence of the horizontal wind vector $(\delta)$ ( $\mathrm{u}$ and $\mathrm{v}$ are the zonal and meridional components of the wind vector, respectively) and the distribution of the fields of temperature $(T)$ and geopotential heights over various isobaric surfaces one day before

\footnotetext{
${ }^{1}$ Nicolaides, K. A., Photiou, G., Savvidou, K., Orphanou, A., Michaelides, S. C., Karakostas, T. S., Charalambous, D., and Kannaouros, C.: The impact of hail storms on the agricultural economy of Cyprus and their characteristics, submitted to Advances in Geosciences, 2008.
}

the event (D-1), on the day of the event (D0) and the following day $(\mathrm{D}+1)$.

The numerical form of the equations in spherical coordinates used for the calculations are (see also Nicolaides et al., 2004):

$$
\begin{aligned}
& \delta=\frac{1}{\mathrm{r} \cos \phi} \frac{\Delta \mathrm{u}}{\Delta \lambda}+\frac{1}{\mathrm{r}} \frac{\Delta \mathrm{v}}{\Delta \phi}-\mathrm{v} \frac{\tan \phi}{\mathrm{r}} \\
& \zeta=\frac{1}{\mathrm{r} \cos \phi} \frac{\Delta \mathrm{v}}{\Delta \lambda}-\frac{1}{\mathrm{r}} \frac{\Delta \mathrm{u}}{\Delta \phi}+\mathrm{u} \frac{\tan \phi}{\mathrm{r}} \\
& \sigma=\frac{g T}{c p}-\frac{p g}{R} \frac{\Delta T}{\Delta p}
\end{aligned}
$$

where $r$, is the radius of earth, $\lambda$ the longitude, $\phi$ the latitude, $g$ the vertical component of the vector of the acceleration of gravity, $c_{p}$ the specific heat of dry air under constant pressure, $p$ the atmospheric pressure and $R$ the universal gas constant. The calculations were made in the original NCEP data spherical co-ordinates, thus avoiding the need for interpolation to a cartesian grid.

The above expression of the static stability index $\sigma$, was used in other studies (e.g. Michaelides, 1987, 1992). The static stability index is always positive and the lower its value, the more unstable the airmass is. For very stable conditions, under the influence of the Siberian High, a value as high as 3 has been observed.

In this paper, only the results for selected levels are presented for brevity. The results presented below in the form of spatial distributions comprise spatial averages of the respective parameter considering all cases in the respective cluster.

Hail occurrences for two consecutive days are not frequent with hail occurrences for three or more consecutive days being rarer; even then, only one of the days is hail of considerable severity. In cases of consecutive hail days, D is defined as the day with the most severe hail occurrence.

The data used for the necessary mathematical calculations were deduced from the NCEP/NCAR global analyses for 00:00 UTC with a grid distance of $2.5^{\circ} \times 2.5^{\circ}$ and the area of the calculations was bounded by the meridians $20^{\circ} \mathrm{W}$ and $50^{\circ} \mathrm{E}$ and the parallels $20^{\circ} \mathrm{N}$ and $65^{\circ} \mathrm{N}$. This resolution is considered as adequate for the synoptic-scale analysis carried out here; data at finer grid resolutions could be used but they would not alter the basic characteristics of the distributions of the dynamic parameters at the scale considered here.

Several thermodynamic indices and parameters of the troposphere over the island of Cyprus, for the respective dates were also calculated, utilizing the radiosonde data from the station of Athalassa $\left(35^{\circ} 09^{\prime} \mathrm{N}, 33^{\circ} 24^{\prime} \mathrm{E}\right)$, situated in the center of the island.

\section{Dynamic study}

During the period 1996-2005, 62 severe hail events were recorded by the Meteorological Service of Cyprus. Most 


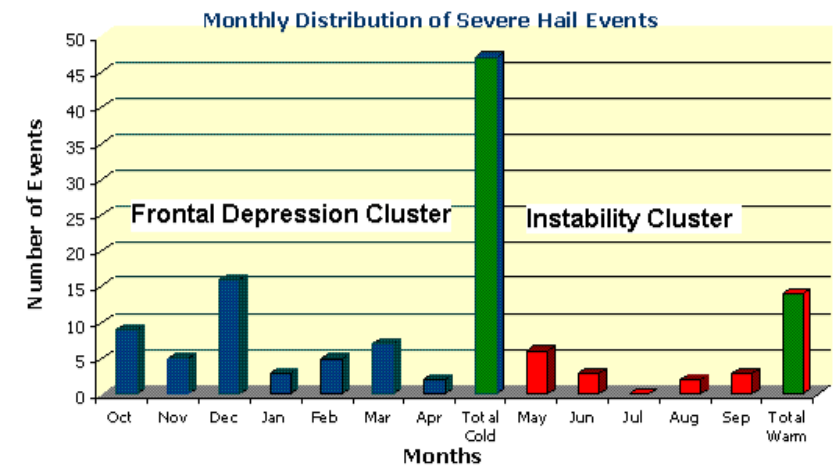

Fig. 1. Monthly distribution of severe hail events during the cold (blue bars) and warm (red bars) period; the corresponding accumulated frequency is also shown (green bars).

of the events (48) occurred during the cold period, when frontal depressions affected the area of the east Mediterranean, while only 14 events were recorded during the hot and dry period. The monthly frequency of hail events is presented in Fig. 1, where the predominance of the hail events during the cold period over the warm, is evident. December contributes with 17 events, while July has no contribution. May, the transitional month from the cold to the hot period, is the main contributor to the thermal instability cluster, with 6 severe hail events.

3.1 Dynamic characteristics of the "Frontal Depression" cluster

On D-1 (one day before the occurrence of the severe hail event) and at the isobaric surface of $500 \mathrm{hPa}$, a midtropospheric trough with its axis just west of the Balkans and extending towards the central Mediterranean is noted, while over the Iberian Peninsula and France, an upper level ridge is observed (Fig. 2a). A typical height of the isobaric layer of $500 \mathrm{hPa}$ over Cyprus area is $5640 \mathrm{gpm}$ and the temperature at the same level is around $254 \mathrm{~K}$.

Over the upper troposphere, at the isobaric lavel of $300 \mathrm{hPa}$, an upper trough is found over the west Balkans, while a weak upper ridge covers mainly west Europe (Fig. 2b). A typical height over the area of Cyprus is 9250 gpm. A maximum of positive relative vorticity over central Mediterranean is also noted, indicating the increased cyclonicity of the upper troposphere.

The distribution of the static stability index (Fig. 3a) over the $850 \mathrm{hPa}$ surface depicts relatively unstable lower tropospheric areas of air over the maritime regions, while the continental areas are covered by a relatively stable lower tropospheric air. The area with the greater instability is the area of the central Mediterranean, resulting from the relatively high sea water temperature, as compared with the other maritime areas. The high values of static stability index of the area of
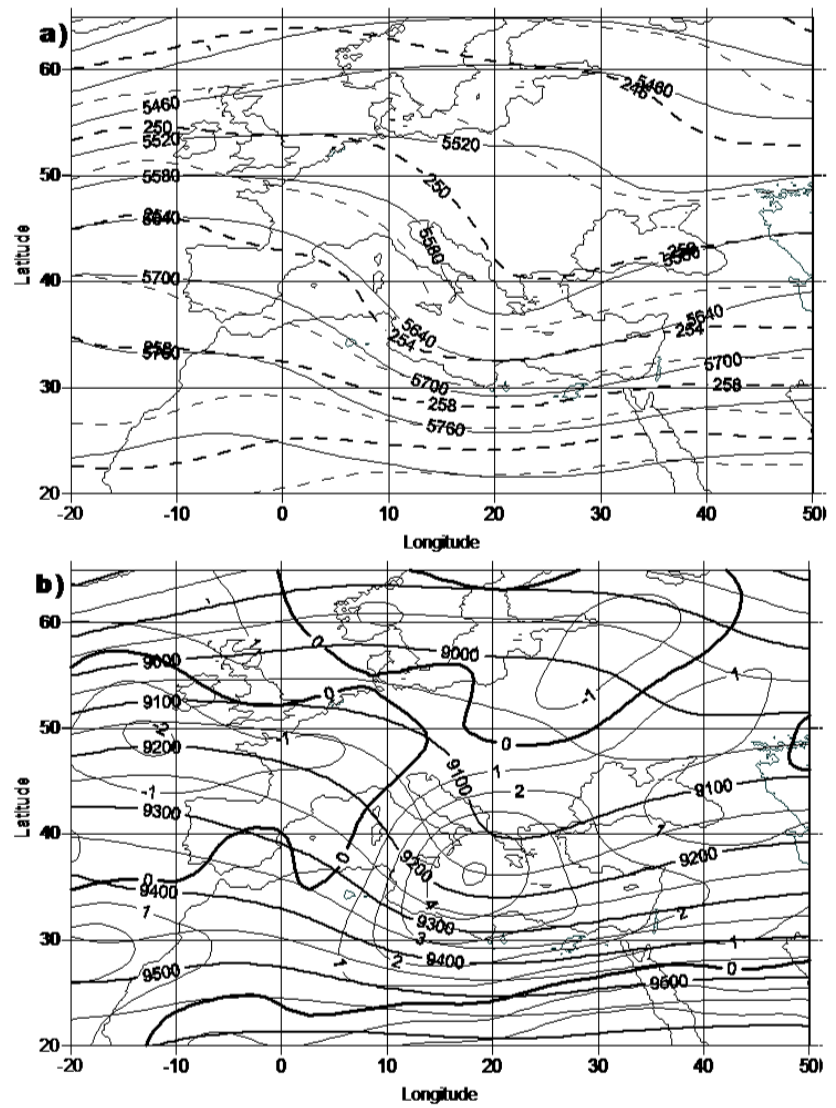

Fig. 2. The average fields of (a) geopotential height (solid lines, in gpm) and temperature (in K, dashed lines) over the isobaric surface of $500 \mathrm{hPa}$, and (b) geopotential height (thick solid lines, in gpm) and relative vorticity (thin lines, in $10^{-5} \mathrm{~s}^{-1}$ ) over the isobaric surface of $300 \mathrm{hPa}$, corresponding to time D-1, for the "frontal depression" cluster.

east Europe and further eastwards are also well marked, as a consequence of the extension of the Siberian high.

From the field of divergence of the horizontal wind vector over the isobaric surface of $850 \mathrm{hPa}$ (Fig. 3b), the area of the Aegean sea and east Mediterranean is an area of lower tropospheric convergence (negative divergence values), while most of the other domains of the study area are areas of lower tropospheric divergence. The combination of the lower level static instability (Fig. 3a) and the convergence of the horizontal wind vector (Fig. 3b) that are noted over central Mediterranean is probably acting as a triggering mechanism for convection, while the upper level divergence (calculated but not shown here) over the same area results in maintaining the cloud formation throughout the tropospheric column.

On the day of the event, namely D0, the upper trough over the isobaric surface of $500 \mathrm{hPa}$ extends over the area of the Aegean sea, reaching Crete (Fig. 4a). At this time, the ridge covers the area of central and west Europe. A typical height over Cyprus of the isobaric surface of $500 \mathrm{hPa}$ is $5600 \mathrm{gpm}$ 

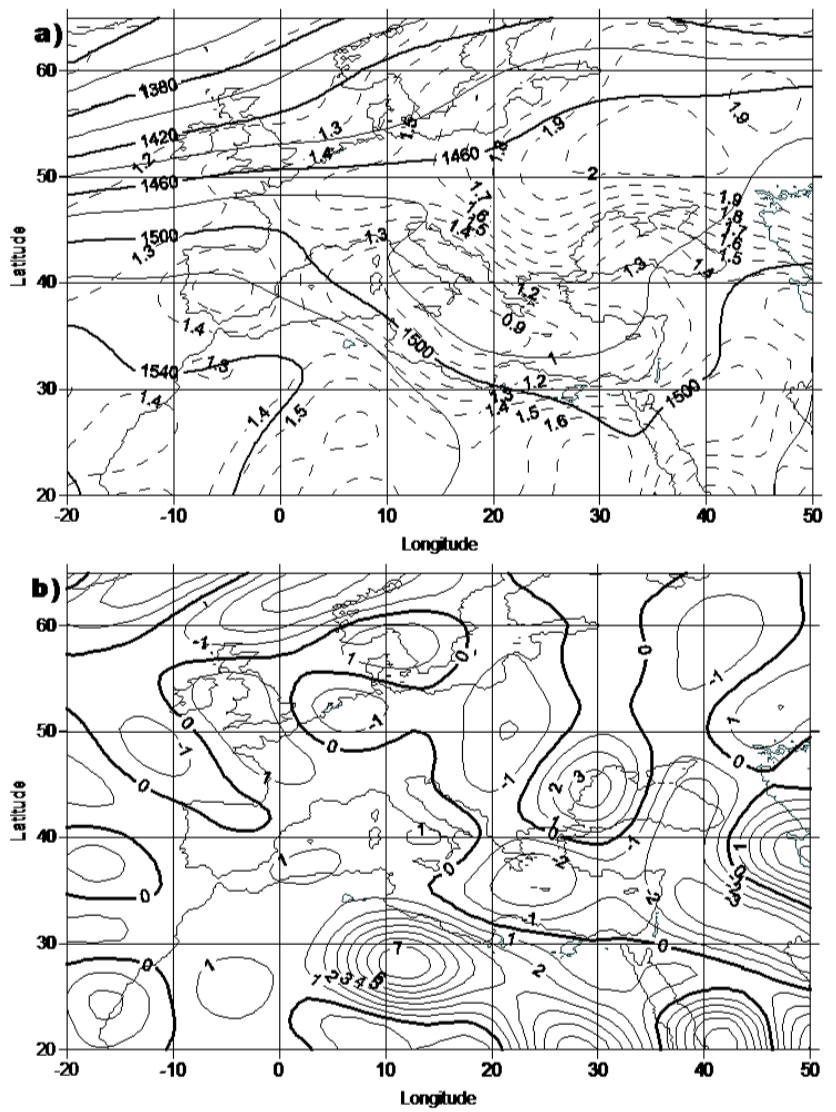

Fig. 3. The average fields of (a) geopotential height (in gpm, solid lines) and static stability index $\left(\mathrm{K}^{2} \mathrm{~s}^{-1}\right.$, dashed lines) over the isobaric surface of $850 \mathrm{hPa}$, and (b) the divergence of the horizontal wind vector (in $10^{-6} \mathrm{~s}^{-1}$ ) over the isobaric surface of $850 \mathrm{hPa}$, corresponding to time D-1 for the "frontal depression" cluster.

(lower by $40 \mathrm{gpm}$, compared with the value over the same area on D-1) and the temperature at the same level and over the same area is $253 \mathrm{~K}$ (lower by only $1 \mathrm{~K}$ compared with the respective value on $\mathrm{D}-1$ ).

Over $300 \mathrm{hPa}$, the upper trough is also found over the Aegean, while the upper ridge is covering west and central Europe (Fig. 4b). A typical height over the area of Cyprus is $9180 \mathrm{gpm}$; deeper by $70 \mathrm{gpm}$, compared with the value on D1. The maximum of relative vorticity is over south Aegean, exceeding $5 \times 10^{-5} \mathrm{~s}^{-1}$ and covering a comparatively wider area.

At the lower isobaric levels $(850 \mathrm{hPa})$ a cut-off low is observed over the area of the Aegean and Crete, while no significant change of the height is observed over the area of Cyprus (Fig. 5a). The static stability index depicts an unstable region, but lesser than on D-1, which extends from central towards the east Mediterranean, almost coinciding with the region of the cut-off low (Fig. 5b).

One day after the occurrence of the severe hail event, namely $\mathrm{D}+1$, the $500 \mathrm{hPa}$ heights continue to decrease
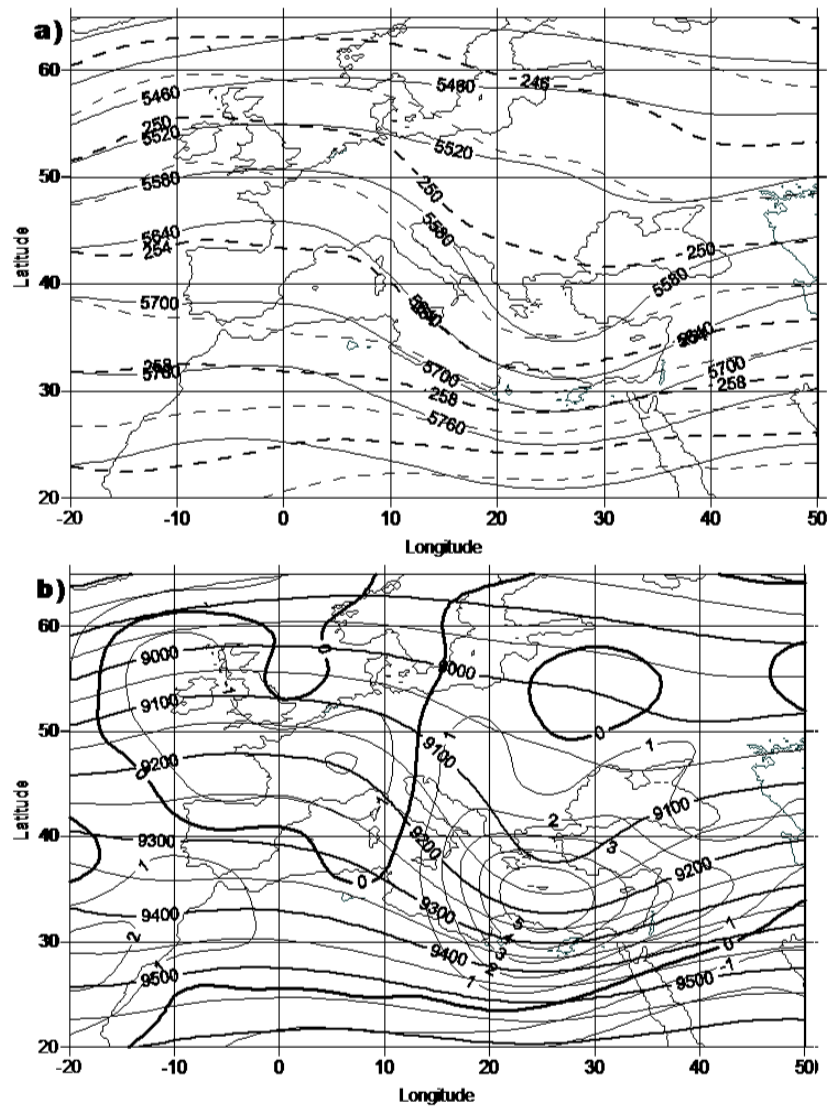

Fig. 4. As Fig. 2, but for D0.

(i.e. $20 \mathrm{gpm}$ lower than D0) but without any significant temperature change (Fig. 6a). Similar results were also found at the $300 \mathrm{hPa}$ level. It is noted that the greater decreases take place at higher levels, thus enhancing the instability of the airmass. Also, the area of maximum relative vorticity is located over the area of Cyprus (Fig. 6b) with the maximum value remaining almost unchanged.

From the distribution of the field of the static stability index over the $850 \mathrm{hPa}$ isobaric level, it is evident that the areas of central and east Mediterranean continue to remain unstable (Fig. 7a). Weak convergence (compared with D0) is observed at $850 \mathrm{hPa}$ over the area of interest, while enhanced lower tropospheric convergence is observed further to the east (Fig. 7b).

\subsection{Dynamic characteristics of the "Thermal Instability" cluster}

On D-1, the synoptic pattern over the study area is similar to the one of the "frontal depression" cluster, with typical height value over Cyprus equal to $5750 \mathrm{gpm}$ (Fig. 8a), (higher than the respective value for the "frontal depression" cluster on D-1). Mean temperature of the mid troposphere is higher than for the frontal cluster, as expected, since the thermal 

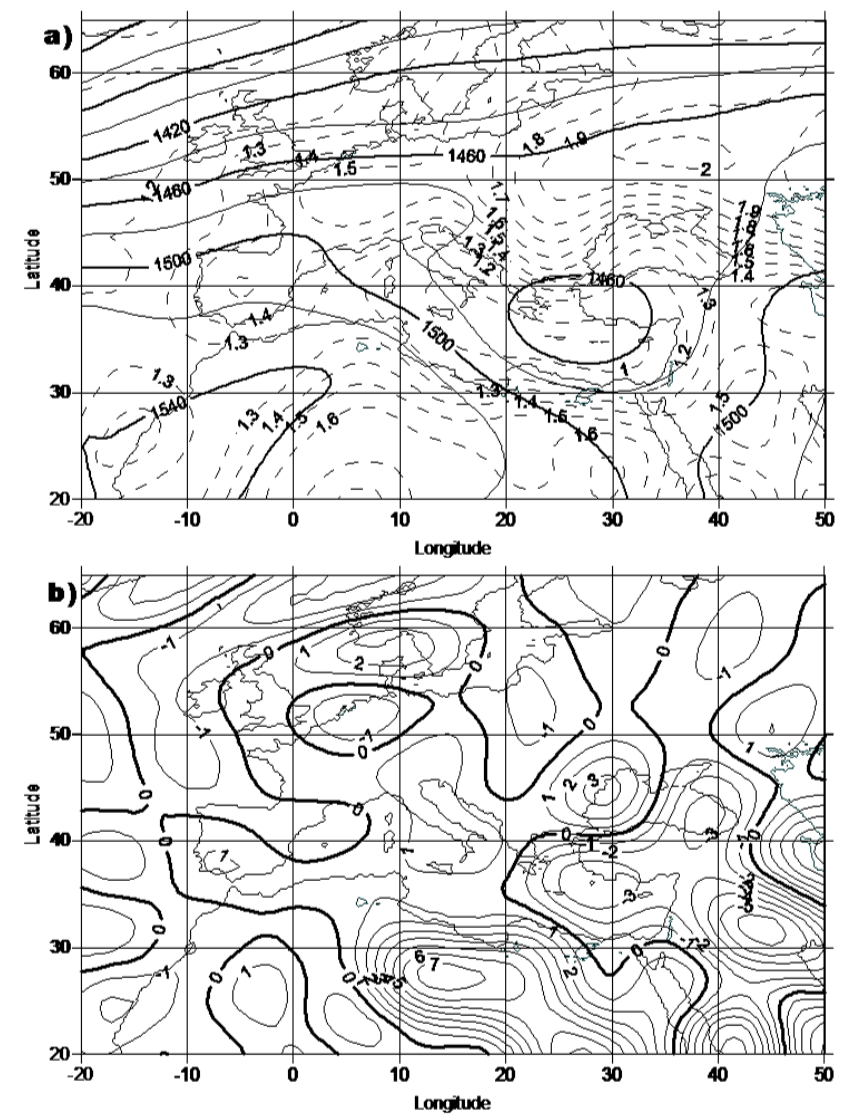

Fig. 5. As Fig. 3, but for D0.

structure of the whole troposphere during the warm period is related with higher values. Over the $300 \mathrm{hPa}$ a typical height value over Cyprus is $9450 \mathrm{gpm}$ (Fig. 8b), almost $200 \mathrm{gpm}$ higher compared with the "frontal depression" cluster on D1.

The field of static stability index for the severe hail events due to "thermal instability" has many differences, compared with the same field of the "frontal depression" cluster. The temperature of the maritime areas during summer is lower than the temperature of the surrounding continental regions, resulting in lower values of tropospheric instability over maritime areas. This is the reason the area of the Sahara desert is found with low values of the static stability index, thus increased low level unstable air (Fig. 9a). Over the area of the east Mediterranean and northeast Africa a static stability index gradient is observed, while a cut-off low is also observed. The distribution of static stability index is not changing significantly at times D0 and at times D+1 (calculated but not presented).

The field of divergence on D-1 presents a wide area of lower tropospheric divergence covering north Africa and central Mediterranean, while the area of the east Mediterranean is an area of relatively low tropospheric divergence (Fig. 9b). The distribution of lower tropospheric divergence
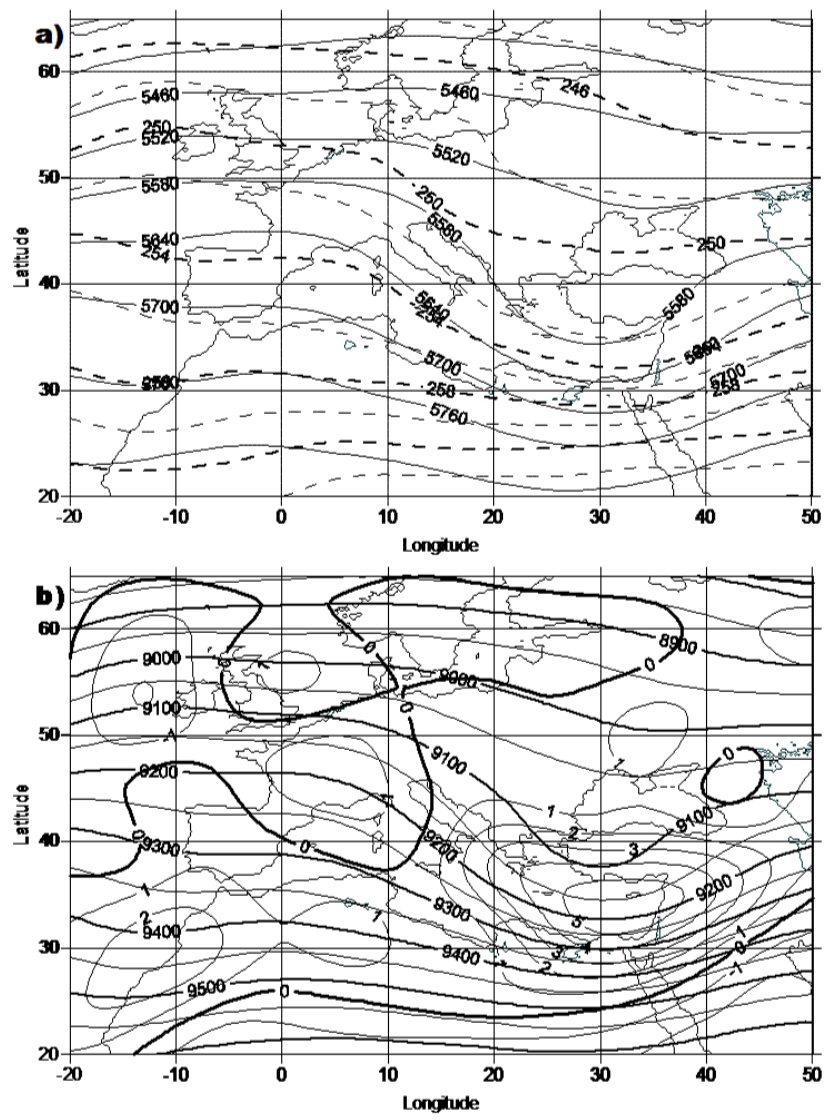

Fig. 6. As Fig. 2, but for D+1.

is not changing significantly at times D0 and D+1 (calculated but not presented).

The distribution of the upper level divergence (calculated for $300 \mathrm{hPa}$, but not presented here) exhibits a broad area of weak convergence, which is covering the area of central and east Mediterranean and central and east Europe. The distribution of upper tropospheric divergence is also not changing significantly at times D0 and D+1.

On the main day of interest, where the severe hail events occurred, the geopotential height distribution over the isobaric surface of $500 \mathrm{hPa}$ represents a sharper upper trough (compared to D-1) extending from Black sea and Asia minor towards the Nile delta (Fig. 10a). A typical height over Cyprus is $5710 \mathrm{~m}$, deeper by $40 \mathrm{gpm}$ compared with $\mathrm{D}-1$.

Over the $300 \mathrm{hPa}$ isobaric layer a weak upper trough is found over the Black sea and north Africa. The distribution of relative vorticity presents positive values over the area of central Mediterranean, the Aegean and east Mediterranean (Fig. 10b). The relative vorticity values are higher at time D0, compared with D-1.

On $\mathrm{D}+1$ the height distribution over the isobaric surface of $500 \mathrm{hPa}$ places the trough further eastwards over Black sea and minor Asia, extending towards the Red sea. A typical height over Cyprus is 5700 gpm (Fig. 11a), 50 gpm lower 

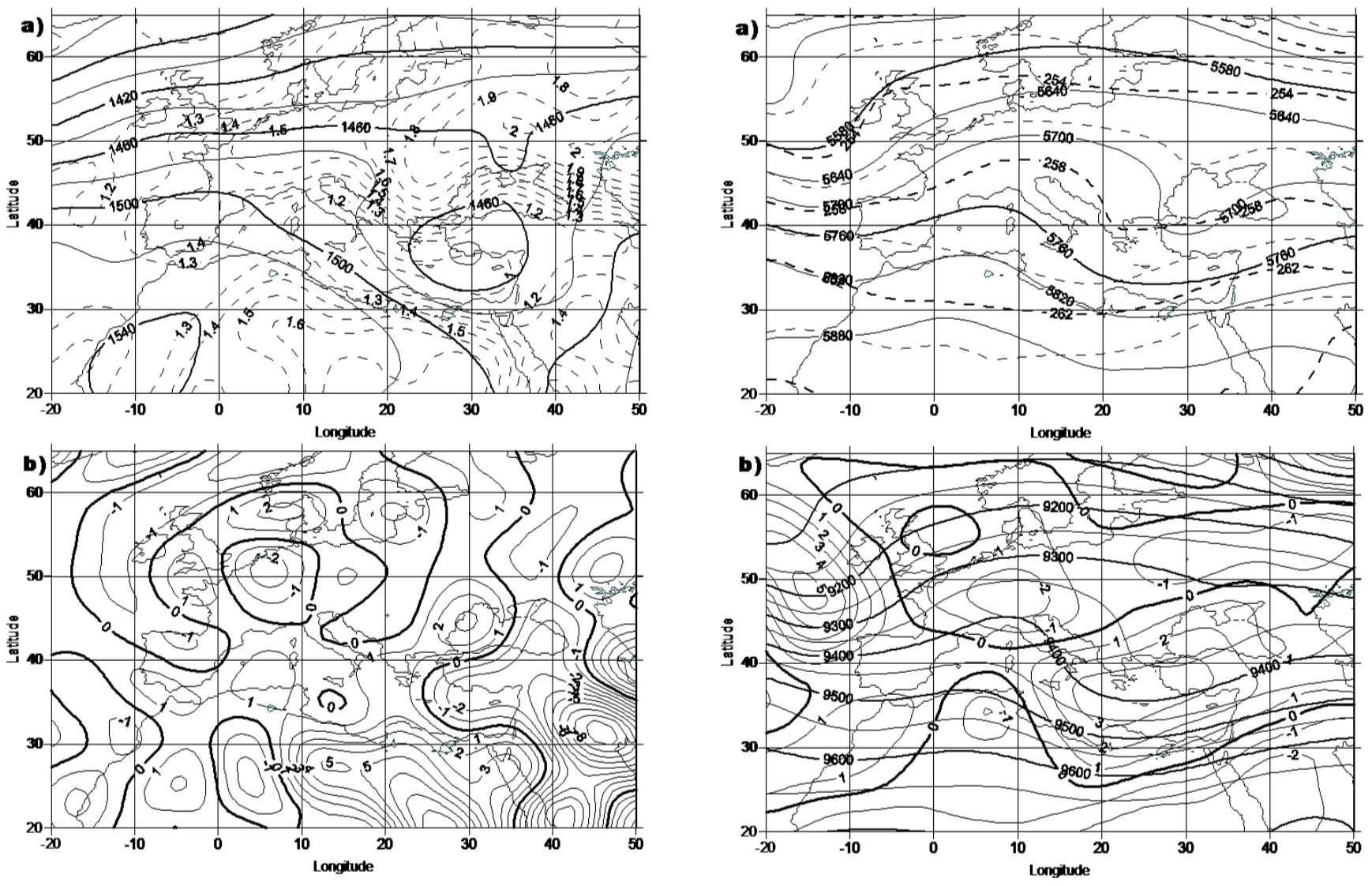

Fig. 7. As Fig. 3, but for D+1.

than on D-1. Comparing the position of the trough's axis at the mid and upper troposphere (Fig. 11a and b), the system seems to become even less baroclinic.

\section{Thermodynamic study}

For the thermodynamic analysis of the atmosphere over Cyprus during the severe hail events studied here, various indices and parameters were calculated for each severe hail event using the radiosonde data from Athalassa station $\left(35^{\circ} 09^{\prime} \mathrm{N}, 33^{\circ} 24^{\prime} \mathrm{E}\right)$ at $12: 00 \mathrm{UTC}$. The indices and the parameters which are widely used and are though to characterize the thermodynamic state of the atmosphere are: the Severe Weather Threat Index (SWEAT), the K Index, the Total Totals Index (TT), the Convective Available Potential Energy (CAPE), the Convective Inhibition (CIN), the Bulk Richardson's Number (BRN), the Precipitable Water (PW), the Wet Bulb Zero degree isotherm (WBZ), the Equilibrium Level (EL), the KO index, the Cloud Top Temperature (CTT) and the vertical extend of the convective cloud above freezing level (EL-FZ) (for the mathematical formulation of these indices and parameters see University of Wyoming, 2007). In addition to these indices, the Freezing Level (FZ) is provided.

Fig. 8. The average fields of (a) geopotential height (solid lines, in gpm) and temperature (in $\mathrm{K}$, dashed lines) over the isobaric surface of $500 \mathrm{hPa}$, and (b) geopotential height (thick solid lines, in gpm) and relative vorticity (thin lines, in $10^{-5} \mathrm{~s}^{-1}$ ) over the isobaric surface of $300 \mathrm{hPa}$, corresponding to time D-1, for the "thermal instability" cluster.

Because the mean storm velocity is correctly estimated from the wind velocity at middle tropospheric level (see Dessens, 1998), the wind velocity at the $600 \mathrm{hPa}$ level is also given in Table 1 . This velocity is 1.32 times stronger during the colder period compared to that of the warmer period.

The range of values of each index and parameter was clustered and the frequency for each "thermal instability" (warm season) and each "frontal depression" cluster (cold season) was calculated. The clustering of the indices and their comparison to the range of values reported in the literature are presented in Fig. 12.

The most representative indices are the KO, the TT, the CIN indices and the PW for which the calculated values are similar to the ones suggested by the literature. The KO index for the $95 \%$ of the events has values which are suggesting that the atmosphere has the potential to give severe thunderstorms. The favorable values range is between -2 and -10 . The values of the TT index range between 45 and 55 for the $85 \%$ of the events and this, according to the severity 
Table 1. Mean seasonal values of each index during the cold and warm period and their ratio.

\begin{tabular}{llll}
\hline Index & Cold Period & Warm Period & Cold/Warm \\
\hline KO $\left({ }^{\circ} \mathrm{C}\right)$ [KO Index] & -5.1 & -7.5 & 0.68 \\
TT $\left({ }^{\circ} \mathrm{C}\right)$ [Total Totals Index] & 50.1 & 49.3 & 1.02 \\
CIN $(\mathrm{J} / \mathrm{kg}$ ) [Convective Inhibition] & -18.3 & -63.2 & 0.29 \\
PW $(\mathrm{cm})$ [Precipitable Water] & 1.8 & 2.7 & 0.68 \\
K $\left({ }^{\circ} \mathrm{C}\right)[$ Precipitable Water] & 20.3 & 27.7 & 0.73 \\
CAPE $(\mathrm{J} / \mathrm{kg}$ ) [Convective Available Potential Energy ] & 797.2 & 767.8 & 1.04 \\
BRN [Bulk Richardson's Number] & 84.1 & 69.5 & 1.21 \\
SWEAT [Severe Weather Treat Index] & 140.7 & 158.3 & 0.89 \\
CTT $\left({ }^{\circ} \mathrm{C}\right)$ [Cloud top temperature] & -42.2 & -37.1 & 1.14 \\
EL-FZ (ft) [The extent of cloud above freezing level] & 19826.0 & 18506.4 & 1.07 \\
WBZ (ft) [Height of the Web-Bulb Zero] & 6095.7 & 9180.2 & 0.66 \\
FZ (ft) [Freezing level] & 7292.2 & 10551.5 & 0.69 \\
Velocity at 600 hPa $(\mathrm{kt})$ & 25 & 19 & 1.32 \\
\hline
\end{tabular}
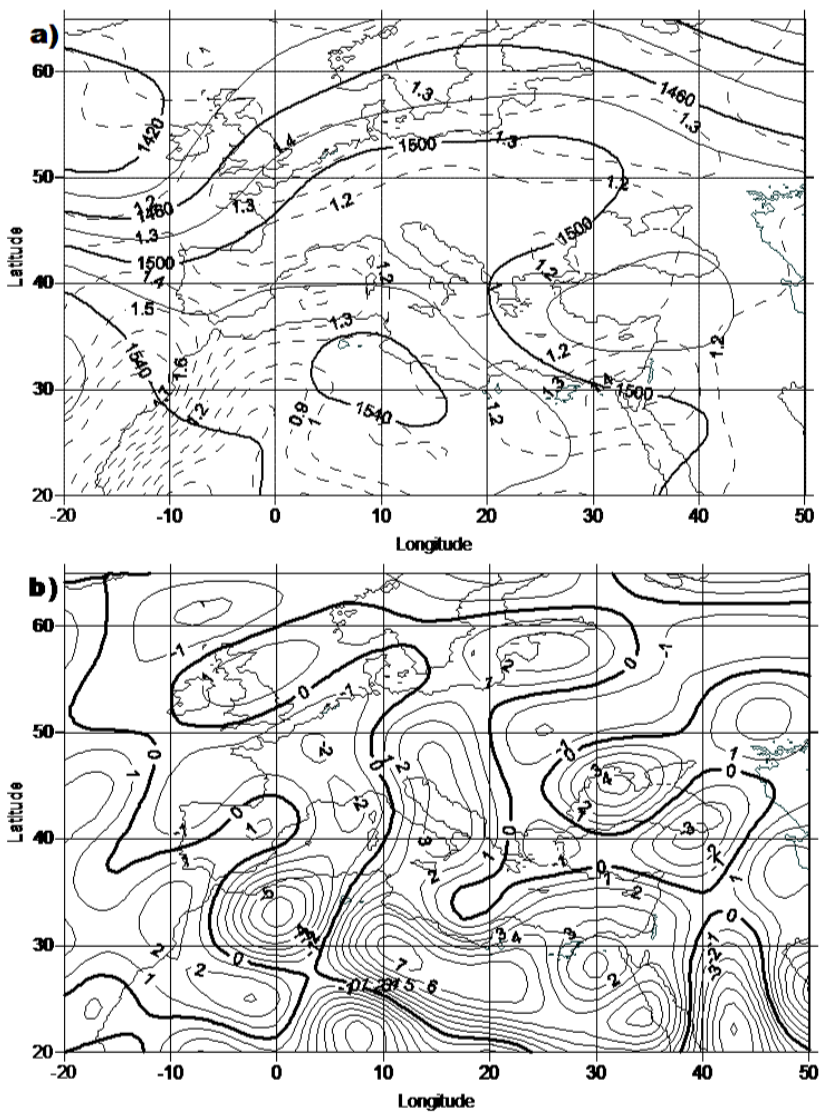

Fig. 9. The average fields of (a) geopotential height (in gpm, solid lines) and static stability index (dashed lines, $\mathrm{K}^{2} \mathrm{~s}^{-1}$ ) over the isobaric surface of $850 \mathrm{hPa}$, and (b) the divergence of the horizontal wind vector (in $10^{-6} \mathrm{~s}^{-1}$ ) over the isobaric surface of $850 \mathrm{hPa}$, corresponding to time D-1 for the "thermal instability" cluster.
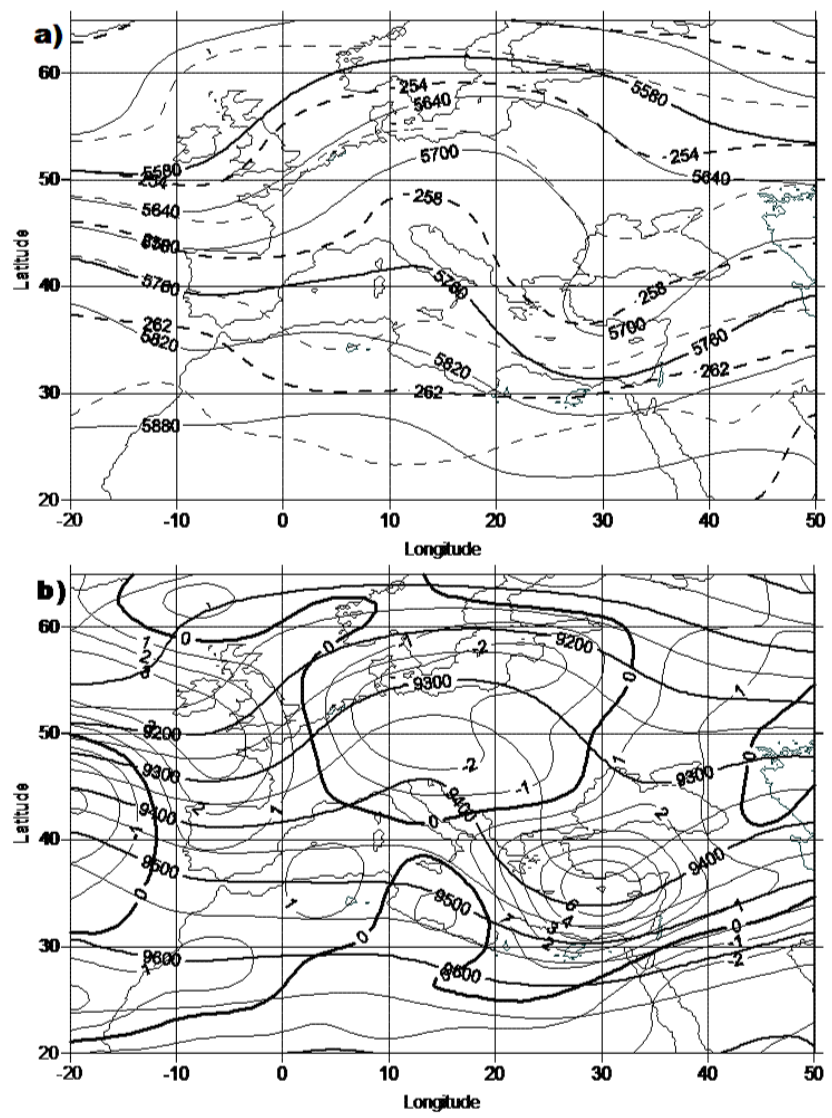

Fig. 10. As Fig. 8, but for D0.

categories given in the literature, is implies increased probability for thunderstorms, which in some cases can be severe. The CIN index values range between 0 and $-48 \mathrm{~J} / \mathrm{kg}$ for the $88 \%$ of the events. The PW has values between $1 \mathrm{~cm}$ and $2.5 \mathrm{~cm}$ for the $75 \%$ of the events, implying a potential for 

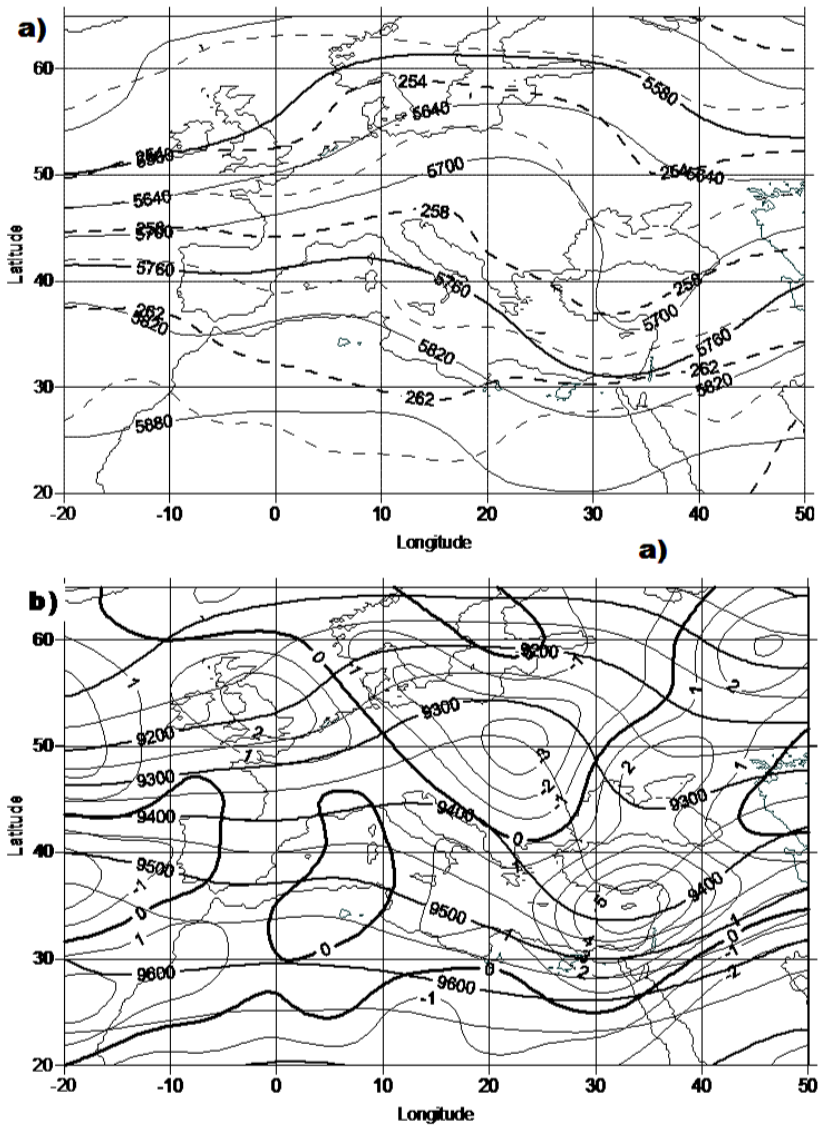

Fig. 11. As Fig. 8, but for D+1.

producing large hail, if other conditions are satisfied. The $\mathrm{K}$ index values, for the $88 \%$ of the events, range between 15 and $35 ; 44 \%$ of them have values between 25 and 35, which is the range of values for moderate weather conditions.

The least representative indices are CAPE, BRN and SWEAT; $70 \%$ of the events have CAPE below $1000 \mathrm{~J} / \mathrm{kg}$; $90 \%$ of the events have SWEAT values between 25 and 250 , while $59 \%$ of the events have BRN values below 20 . Within the aforementioned ranges, the calculated values are below the critical thresholds for moderate thunderstorm activity and in some cases no thunderstorm development was suggested. This is probably due to the time difference of the hail event and the radiosonde, as well as the different location of the event and the radiosonde station.

Finally, the CTT and EL-FL for around 50\% of the events have values resulting in moderate to severe thunderstorms with hail. For all indices the frequencies of each cluster differ from cold to warm season, due to the variation of the thermal structure of the troposphere.

In order to detect any possible differences, as well as the representative values of each index during the cold and warm period, a second approach was employed; the mean values of each index for the cold and warm period were calculated and afterwards, the ratio of the mean values during the cold period over the one during the warm period was studied. The results are given in Table 1.

During the cold season the values of the TT index and the CTT, are slightly higher than the one of the warm period by $2 \%$ and $14 \%$, respectively, while the $\mathrm{K}$ and $\mathrm{KO}$ indices are lower by around 30\% of the warm period values. During the cold period, the values of $\mathrm{FZ}$ and the $\mathrm{WBZ}$ are lower than the values of the warm period by around $30 \%$ and $35 \%$, respectively and this is due to the seasonal changes of the thermal structure of the atmosphere. The values of the EL are slightly lower by around $5 \%$, while the values of the vertical extend of the cloud above the freezing level (EL-FZ) are slightly higher by $7 \%$.The SWEAT index is higher during the warm period by around $10 \%$ while the BRN is lower by around $20 \%$. The PW values during the cold period are lower than the values during the warm period by around $30 \%$. The values of CAPE are similar during the cold and the warm period, only slightly higher during the cold period (by $4 \%$ ), while the CIN is much lower during the cold period by around $70 \%$.

The mean values of the TT, KO, WBZ, CTT, EZ-FZ, PW and $\mathrm{CIN}$ for the cold period and of $\mathrm{K}$ for the warm period are suggesting moderate to severe thunderstorms with hail. The other indices are suggesting weak potential of the atmosphere to give thunderstorm with hail.

\section{Agro-economic impact aspects}

The Agricultural Insurance Organization of Cyprus is a semigovernmental, non-profit oriented organization and offers compulsory insurance cover to farmers whose insured crops suffer damages from unavoidable natural hazards. The premium paid is shared between the Government and the individual farmer whose crop is insured. The total amount for all compensations to farmers during the years 1996 to 2005 amounts to 80200.5 KEuros; compensations were paid for a large spectrum of hazards causing crop damage; almost all causes are attributed to weather hazards, such as hail, drought, wind, heat wave, floods and frost. The amount paid to farmers due to hail damages during the above mentioned period is 22751.4 KEuros. Therefore, the compensations due to hail occurrences amount to $28 \%$ of the total compensations paid. To appreciate the compensations' level with respect to the GNP, (Gross National Product was 8692 billion by 2000) it is noted that the annual average compensation paid represents just $0.026 \%$ of the GNP. This might at first appear as having a very small impact on the country's economy; however, it is interesting to note that the damages incurring on the agricultural economy affect farmers whose major income is from their (mostly) single crop activities and therefore such damages from hail and the subsequent compensations are quite significant on the individual farmer's level.

Figure 13 displays comparatively the compensations paid for all damages versus the compensations paid due to hail 

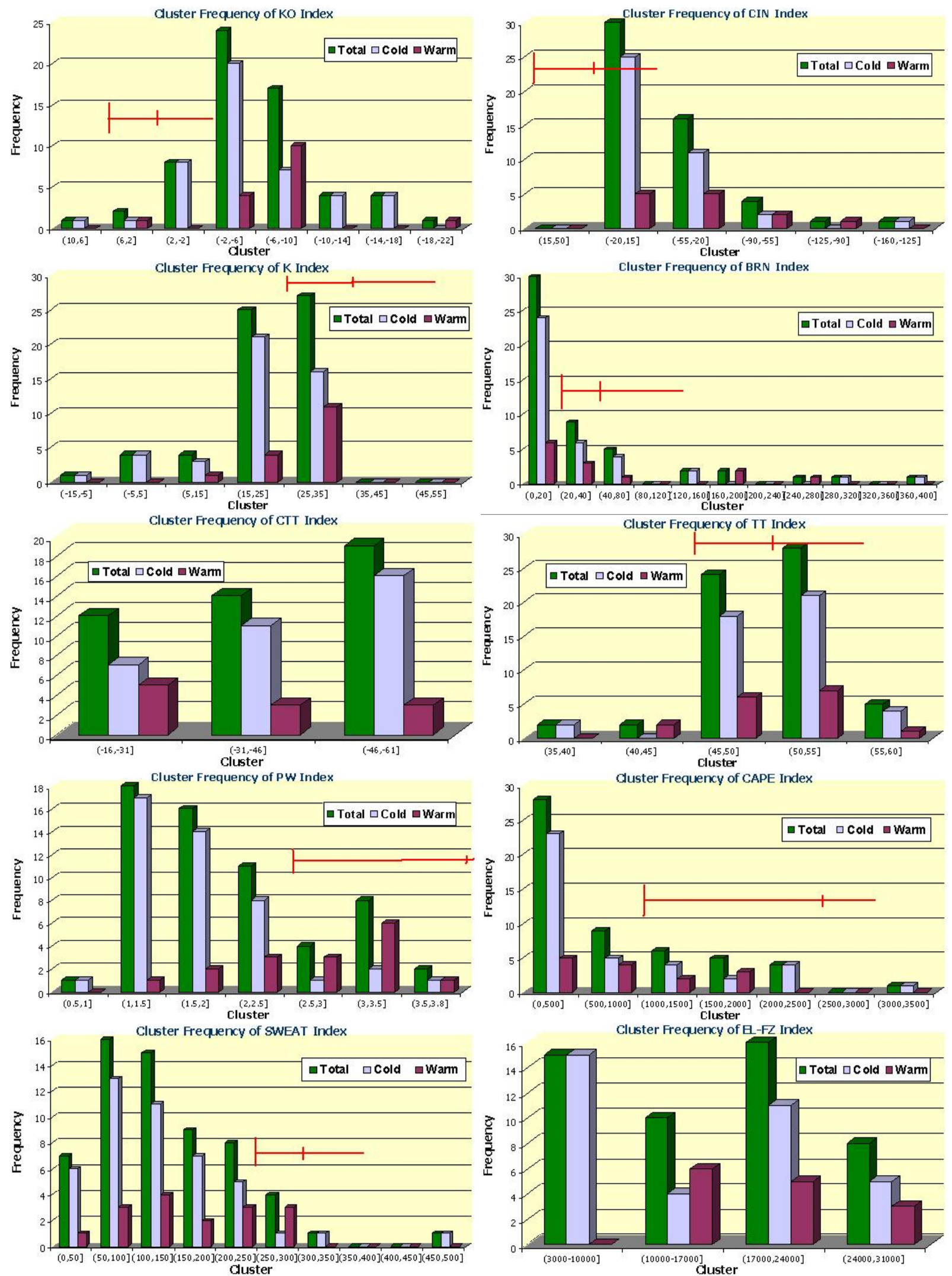

Fig. 12. Cluster frequency of the severe hail events for each thermodynamic index during the cold (blue), the warm (purple) period and for the total number of events (green). The red lines indicate the lower and upper thresholds of the moderate and severe category. 


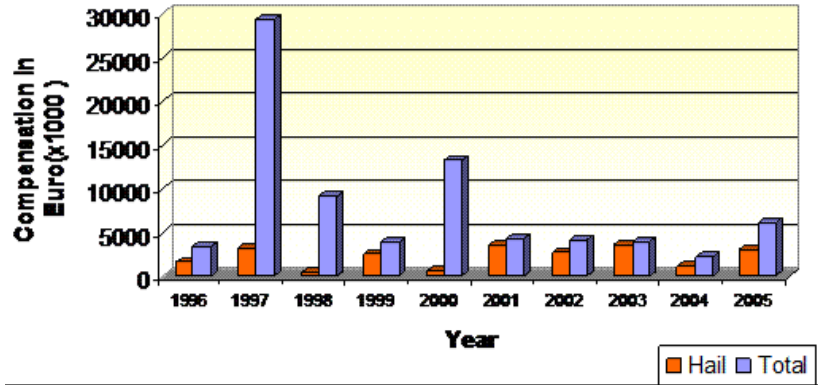

Fig. 13. Annual total compensations paid versus the compensations paid due to hail.

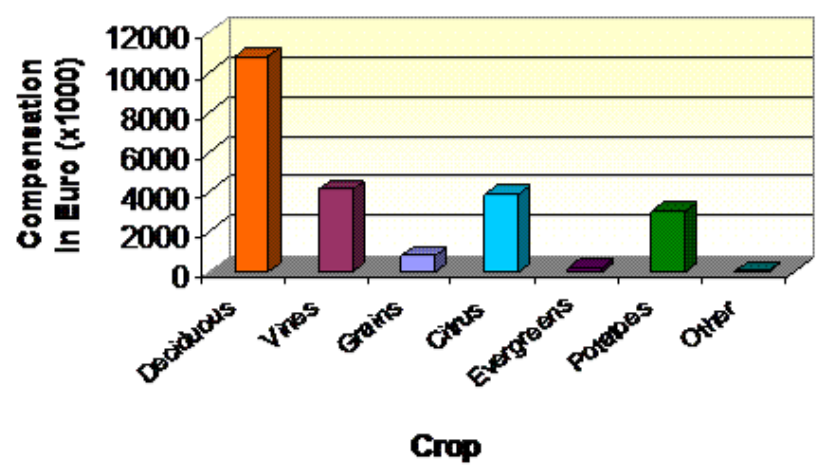

Fig. 14. Compensations paid due to hail damages on a crop by crop basis.

losses on a yearly basis. It can be seen from this figure that the yearly amount of compensation is paid due to hail represents a substantial amount of the total in most of the years in the period 1996-2005.

It is also interesting to see how the compensation from hail losses and damages is distributed among the various crops covered by the AIO compensation scheme. Figure 14 displays this sharing of the compensation paid. A large share goes to the deciduous trees followed by the vines and citrus. The potato crops come fourth, with a much smaller amount paid to grain crops. As mentioned above, growers of the respective crops depend mostly on single crops for their income. For example, damages to deciduous fruit trees are specific to farmers on the mountainous regions of the country where these trees grow almost exclusively.

\section{Concluding remarks}

Hail is a hazardous weather element often accompanying a thunderstorm, resulting either from thermal or from frontal instability. Severe hail events not only harm agricultural production but can also cause problems to several of human activities, like transportation and construction. In Cyprus, severe hail events are not rare, with 62 events being registered in a 10 year period. More common are the severe hail events which resulted from frontal activity over the area (amounting to 48), during the cold period, compared to the thermal instability caused severe hail events (amounting to only 14).

Baroclinic instability is the triggering mechanism for the cold months' severe hail events, while not only thermal instability is the triggering mechanism for warm months, since a weak upper trough is found to be essential. The warm sea during cold season triggers and maintains lower tropospheric convergence.

It is beyond the scope of this paper to add to the knowledge of physics of hail, a subject which is documented elsewhere; rather, the aim of this study was to shed light on various aspects of the severe hail occurrences on the scale of a country, in an attempt to understand the atmospheric conditions and synoptic circumstances leading to hail events. In this respect, the dynamic and thermodynamic characteristics of severe hail events were studied. The results presented above are diagnostic in nature but can comprise a useful guidance to forecasting these events (see also Nicolaides et al., 2006). In a further expansion of such an approach, a comparison of the results of the present study with long-term averages of the respective spatial distributions (e.g. Flocas et al., 2001) could reveal the extent to which deviations from these average distributions can be of significance to adequately identify signatures of hail occurrences.

Agricultural production is the economic domain which is mostly affected by hail storms. Damages due to hail which are compensated by the AIO amount to 22751.4 Euros; this compensation represents $28 \%$ of the total agricultural compensations paid due to adverse growing conditions (a considerable number of which are directly attributed to weather).

Although the present study focused on the synoptic-scale features, it is well known that other factors (of sub-synoptic scale) have an important role to play, too. Such contributions are currently under study, as for example, the sea breeze convergence zone which is known to have a local contribution to the occurrence of severe hail events of the "thermal instability cluster".

The impact of the hail occurrences on the local economy have briefly been considered in terms of the compensations paid to farmers due to hail damages on their crops. All of the above can form the background for taking any decisions on possible mitigation measures and policies regarding this particular natural hazard (e.g. hail suppression, speeding of the harvest, crop diversion, improvement of forecasting methods etc).

Acknowledgements. This study was undertaken within the framework of project FLASH which is funded by the European Union (Sixth Framework Programme, Contract No. 036852).

Edited by: A. Mugnai and M.-C. Llasat

Reviewed by: K. Lagouvardos and another anonymous referee 


\section{References}

Blanchet, G.: Le temps au Liban. Approche d'une Climatologie Synoptique, Thèse 3ème Cycle, Lyon. T.I., 447 (text et tab.) \& T.II (Atlas), 1976.

Dessens, J.: A physical evaluation of a hail suppression project with silver iodide ground burners in southwestern France. J. Appl. Meteorol., 37, 1588-1599, 1998.

El-Fandy, M. G.: Barometric Lows of Cyprus, Q. J. Roy. Met. Soc., 72, 291-306, 1946.

Flocas, H. A., Maheras, P., Karacostas, T. S., Patrikas, I., and Anagnostopoulou, C.: A 40-year climatological study of relative vorticity distribution over the Mediterranean, Int.J. Climatol., 21, 1759-1778, 2001.

Jacobeit, J.: Variations of trough position and precipitation patterns in the Mediterranean area, J. Climatol., 7, 453-476, 1987.

Kallos, G. and Metaxas, D. A.: Synoptic processes for the formation of Cyprus lows, Riv. Meteorol. Aeronau. XL(2-3), 121-138, 1980.

Maheras, P.: A factorial analysis of Mediterranean precipitation, Arch. Meteor. Geophy. B., 36, 1-14, 1985.

Maheras, P., Flocas, H. A., Anagnostopoulou, C., and Patrikas, I.: On the vertical structure of composite surface cyclones in the Mediterranean region, Theor. Appl. Climatol., 71, 199-217, 2002.

Michaelides, S., Nicolaides, K., and Karacostas, T.: Statistical characteristics of the cold season depressions over the area of Cyprus, Meteorologický asopis 7, 61-66, 2004.
Michaelides, S. C.: Limited area energetics of Genoa cyclogenesis, Mon. Weather Rev., 115, 13-26, 1987.

Michaelides, S. C.: A spatial and temporal energetics analysis of a baroclinic disturbance in the Mediterranean, Mon. Weather Rev., 120, 1224-1243, 1992.

Nicolaides, K.: Synoptic and dynamic study of the depression cases affected the wider area of Cyprus during cold months. PhD thesis, Aristotelian University, Thessaloniki, Greece (in Greek), 2005.

Nicolaides, K., Michaelides, S., and Karacostas, T.: Spatial distribution of some dynamic parameters during the evolution of selected depressions over the area of Cyprus, Int. J. Climatol., 24, 1829-1844, 2004.

Nicolaides, K., Michaelides, S., and Karacostas, T.: Synoptic and dynamic characteristics of selected deep depressions over Cyprus, Advances in Geosciences, 7, 195-180, 2006.

Petterssen, S.: Weather analysis and forecasting. McGraw-Hill, 1956.

Radinovic, D.: Mediterranean cyclones and their influence on the weather and climate, program on short and medium range weather prediction research (PSMP), W.M.O. Sofia, 1987.

Reiter, E.R.: Handbook for forecasters in the Mediterranean. Naval Postgraduate School, Monterey California, USA, 1975.

University of Wyoming: http://weather.uwyo.edu/upperair/ sounding.html, last access: 15 December 2007. 